Conclusion Findings suggest that long work hours, especially among men with a history of work at night, may influence prostate cancer risk.

\section{RF-327 REINCORPORATION TO LABOUR MARKET OF A SAMPLE OF CANCER SURVIVORS IN CATALONIA (SPAIN) BETWEEN 2012 AND 2015. A COMPARISON BETWEEN WOMEN AND MEN.}

${ }^{1}$ Amaya Ayala-Garcia, Laura Serra, Cristina Portellano-Ortiz, Fernando G Benavides. ${ }^{1}$ Universitat Pompeu Fabra, Spain

\subsection{6/OEM-2021-EPI.365}

Introduction Incidence and survival rates of cancer have increased in the last decade. The number of people diagnosed with cancer in the workplace are expected to increase steadily. Objective To describe the employment status of a sample of salaried workers who suffered a previous sickness absence (SA) due to cancer, up to 4 years after diagnosis.

Methods Cohort study based on a sample of workers $(\mathrm{N}=145,614)$, affiliated with the Spanish Social Security System, residents in Catalonia, with at least one SA episode due to a cancer between 2012 and $2015(\mathrm{~N}=516$; average age 50 in men and 47 in women). Individuals were followed up from the end of the SA episode, and future employment status was assessed in five outcomes: early retirement before age 65, partial retirement, permanent disability, unemployment with subsidy and employment. Last available working outcome was assigned to each individual and Chi-square test was used to assess differences between sexes.

Results For both, men $(\mathrm{N}=225)$ and women $(\mathrm{N}=291)$, employment was the most frequent outcome at the end of the period $(73.5 \%$ and $82.7 \%)$ followed by permanent disability $(10 \%$ and $7.6 \%)$. In men, early retirement was found to be higher than in women $(7.8 \%$ vs $3.8 \%)$. Women experienced a very low proportion of partial retirement $(1.4 \%)$ compared to men (4.35\%). All differences between sexes were found to be statistically significant $(\mathrm{p}<0.05)$.

Conclusion Preliminary results show that most of the people who survive a cancer go back to employment. However, there is a high proportion of people who get a permanent disability, retire or become unemployed, with differences between sexes. Characterizing reincorporation to labour market of people who survive a cancer allows us to determine how the disease affects survivors and society in order to understand where public policy can act.

\section{Disease Surveillance}

\section{RF-102 WORK-RELATED HEAD INJURY AND INDUSTRY SECTORS IN FINLAND - CAUSES AND CIRCUMSTANCES}

${ }^{1}$ Ari Kaukiainen, Aura Heimonen, Kari Nousiainen, Heikki Lassila. 'University of Helsinki, Finland

\subsection{6/OEM-2021-EPI.366}

Objectives Despite of continuous development of occupational safety, there is still an excess of work-related head injuries. Prevention of head injuries can be promoted by evaluating risks and pathways of events preceding injuries.
Methods In Finland, more than 90\% of employees are insured with inclusive mandatory coverage. Data on occupational head injuries in 2010-2017 was obtained from a workers' compensation insurer database. European Statistics on Accidents at Work (ESAW) variables represented the conditions of the accidents and characteristics of the injury. Risk factors, contributing events, and injury mechanisms in 20 industry sectors, based on the Statistical classification of economic activities in the European community (NACE) were analysed.

Results Among the 32,898 cases, the most common area affected was eyes (49.6\%), followed by brain and cranial nerves and vessels (21.0\%). The highest incidence of head injuries was in construction (15.7 per 1,000 insurance years). Construction, manufacturing, and human health and social work activities stood out by their distinctive ESAW category counts. 'Working with hand-held tools' (odds ratio [OR] 2.99, 95\% confidence interval $[\mathrm{CI}] 2.81-3.18)$ in construction and 'operating machine' (OR 3.58, 95\% CI 3.22-3.98) and 'working with hand-held tools' $(2.52,2.37-2.67)$ in manufacturing predicted head injury. There were over tenfold increased risk related to parameters of violence and threat in health and social work activities.

Conclusions Risks and pathways preceding head injuries varied considerably in the 20 industry sectors. The highest head injury rates were in construction and manufacturing. Violence emerged as a major risk factor in human health and social work activities.

\section{RF-203 OVERLAPPING VULNERABILITIES IN WORKERS OF THE ELECTRONICS RECYCLING INDUSTRY FORMAL SECTOR}

'Diana Ceballos, France Labrèche, Daniel Côté, Robert Herrick, Bouchra Bakhiyi, Sabrina Gravel, Michael Flynn, Joseph Zayed. 'Boston University School of Public Health, United States

\subsection{6/OEM-2021-EPI.367}

Objective Vulnerabilities in workers performing electronics recycling (e-recycling) in the informal sector worldwide have been well documented. However, the growing electronics waste industry formal sector still brings many challenges to protect the health of workers and their environment, even in high income countries. This presentation aims to draw attention to the overlooked vulnerabilities faced by the workers of the e-recycling industry in high-income countries and to discuss the potential impact on health inequalities experienced by these workers.

Methods We performed a review of the peer-reviewed and gray literature in the e-recycling industry.

Results Workers in the e-recycling formal sector often come from sectors of society known to be more susceptible to exposures and health effects, such as young workers, immigrants or ethnic minorities, prisoners, and workers with mental or physical disabilities.

Discussion This phenomenon in high-income countries is not restricted to the e-recycling industry alone. It is rather a symptom of more generalized macro socio-economical phenomena of challenges in line with the new gig economy and changes in the global market, and their consequences on the solid waste sector. Continued efforts to strengthen the inclusion of social aspects of health into the complex interaction of the structural vulnerabilities met by e-recycling workers will be essential to anticipate and prevent health issues in this 